\title{
Adsorption Capacity and Mechanism of Expanded Graphite for Polyethylene Glycol and Oils
}

\author{
XIU-YAN PANG \\ College of Chemistry and Environmental Science, \\ Hebei University, Baoding 071002, People' Republic of China. \\ pxy833@163.com
}

Received 6 January 2010; Accepted 2 March 2010

\begin{abstract}
Expanded graphite (EG) shows higher adsorption capacity for oils such as salad oil and SD300 oil than polyethylene glycol (PEG) with different MW (4000, 10000, 20000). To illustrate their different adsorption mechanism, adsorption capacities of EG for these pollutants are firstly detected. And then stepwise adsorption for oils is carried out with EG which has been saturated first by PEG with different MW. Then difference between stepwise adsorbance of oil is checked with deviation analysis. Scanning electronic microscopy (SEM) analysis is used to show structure difference of EG adsorbed different adsorbates. It is testified adsorption isotherms of PEG are all type I, PEG molecules lay flat on EG surface and equilibrium adsorbance decrease with the increase of PEG MW. Adsorbance for SD 300 oil and salad oil can reach 131.3 $\mathrm{g} / \mathrm{g}$ and $127.8 \mathrm{~g} / \mathrm{g}$ respectively. Deviation analysis for stepwise adsorbance of oil shows no statistical significance. EG saturated firstly by PEG, still has an average adsorption capacity of $98 \mathrm{~g} / \mathrm{g}$ for SD300 oil and $85 \mathrm{~g} / \mathrm{g}$ for salad oil and it does not change with the initial PEG concentration. SEM photos illustrate the adsorption of oil on EG is mainly filling. In the adsorption of PEG water solution, there is severe breakage of the V-type pore and shrinkage of the particle.
\end{abstract}

Keywords: Expanded graphite, Stepwise adsorption, PEG wastewater, Oil, Adsorption mechanism.

\section{Introduction}

Accidents of oil tankers and oiliness wastewater have caused serious environmental problems. It gives not only environmental problem but also great loss of energy resource. Thus, effectively recovering technology is needed. Adsorption treatment with porous material ${ }^{1}$ is one of current methods. Wide application of PEG in industries, such as medicament, metal forming, cosmetics and food makes, it become another major wastewater source. 
EG is a kind of porous material, it has attracted attention of scientists and engineers as an adsorbent with a high adsorption capacity for organic materials, such as heavy oil and organic molecules ${ }^{2-4}$. Pores in EG are described using a 4-level model ${ }^{5}$, these four level pores are expected to act quite differently in adsorption performance of EG for various liquids. In the adsorption of heavy oils ${ }^{6,7}$, large open space among entangled worm-like particles, first-level and second-level pores of EG are found to be very important, but microporous or mesoporous pores are useless. Adsorbance of grade A heavy oil was detected as $83.0 \mathrm{~g}$ on $1.0 \mathrm{~g}$ of EG with a bulk density ${ }^{8}$ of $0.006 \mathrm{~g} / \mathrm{cm}^{3}$ and the pores with the size of 0.004 to $4 \mu \mathrm{m}$ was too low to explain the adsorption capacity of the measured oil.

In the adsorption of PEG with active carbon as adsorbent, Zhao et al ${ }^{9}$ reported the adsorbed molecules lay flat on active carbon surface and isotherms are all Langmuir type. Chang $e t a l^{10,11}$ indicated a high adsorption capacity of $303 \mathrm{~g} / \mathrm{g}$ during 14 days for PEG with an average MW of 6000 from copper electroplating solutions at 288-313 K. Contrast to the adsorption on activated carbon, basic study of PEG on EG is scarce. The porous structure of EG makes it have adsorption capacity for PEG. Therefore, purpose of this study is: with salad oil, Thermal oil, PEG $(4000,10000,20000)$ as reference compounds, based on adsorption experiment, to detect the adsorption capacity of EG for these adsorbates and to testify their different adsorption mechanism on EG. SEM observation, stepwise adsorption and deviation analysis of stepwise adsorption are carried out simultaneously.

\section{Experimental}

EG is firstly prepared according to literature ${ }^{12}$ and then it was expanded in KSW heating oven (Huacheng Oven Factory of Tientsin) at $900{ }^{\circ} \mathrm{C}$. Structural parameters of EG were characterized by bulk density, specific surface area and pore cubage as listed in Table 1. These data were detected with Pore Master 60GT instrument (Quantachrome Instruments, USA) under varying pressures of 0.818 PSIA to 59667.199 PSIA.

Table 1. Structural parameter of expanded graphite

\begin{tabular}{|c|c|c|c|c|c|c|c|}
\hline 爸藏 & 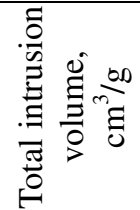 & 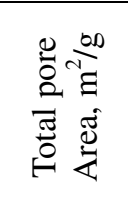 & 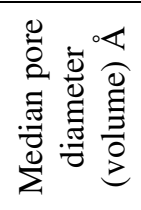 & 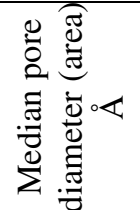 & 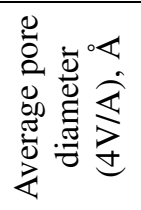 & 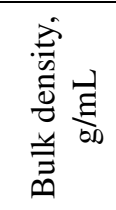 & $\begin{array}{l}\stackrel{\overrightarrow{0}}{0} \\
0 \\
0 \\
0\end{array}$ \\
\hline 320 & 30.1145 & 1044.99 & 163117 & 44 & 1153 & 0.0308 & 92.73 \\
\hline
\end{tabular}

Adsorbates characteristic

Thermal oil and salad oil were used in the experiment, the viscosity was determined as 0.059 and $0.016(100 \mathrm{~mL} / \mathrm{g})$ repectively at $25^{\circ} \mathrm{C}$ with an Ubbelohde viscometer. Pure substances were used in the experiment.

PEG with different MW of 4000, 10000, 20000 was used as adsorbate. They are purchased from the Fu Cheng Chemical Factory (Catalog No.20050707). Simulated PEG wastewater is prepared by dissolving PEG in distilled deionized water at various concentrations. In quantitative analysis ${ }^{13}$, Dragendoff was used as colored reagent of PEG and absorbance of the colored complex (color reaction lasted $10 \mathrm{~min}$ ) was detected with T6 New Century UV spectrophotometry (Puxi Tongyong Instrument Limited Company of Beijing). Absorbance values were recorded at the wavelength for maximum absorbance $\left(\lambda_{\max }\right)$ (as listed in Table 2) and its solution was initially calibrated for concentration in terms of absorbance units. 
Table 2. MW and maximum absorbance wavelength of PEG

\section{Adsorption for oil}

\begin{tabular}{ccc}
\hline \multirow{4}{*}{ PEG } & Molecular weight & $\lambda_{\max }, \mathrm{nm}$ \\
\cline { 2 - 3 } & 4000 & 508 \\
& 10000 & 512 \\
& 20000 & 510 \\
\hline
\end{tabular}

Batch adsorption experiments have been carried out with about $0.200 \mathrm{~g}$ EG $\left(m_{l}\right)$ and $100.0 \mathrm{~mL}$ oil in $250 \mathrm{~mL}$ flask with plug and mixed well gently. At different intervals of time, EG is filtrated with wire gauze and quantified for estimation of balance adsorbance for oil. Balance time is detected as about $24.0 \mathrm{~h}$ at $25{ }^{\circ} \mathrm{C}$. Incremental weight of wire gauze is calculated as $m_{2}$. Adsorbance $q_{e}$ of oil on EG is calculated according to equation (1):

\section{Adsorption for PEG}

$$
q_{e}=\left(m_{2}-m_{1}\right) / m_{1}
$$

Static adsorption experiments of PEG have been undertaken by taking about $0.200 \mathrm{~g}\left(m_{1}\right)$ EG with $100.0 \mathrm{~mL}(\mathrm{~V})$ PEG solution of known initial concentrations $C_{0}$ in different conical glass flasks. Adsorption equilibrium time at $25{ }^{\circ} \mathrm{C}$ was about 40 min for PEG (4000), about $60 \mathrm{~min}$ for PEG (10000) and about $180 \mathrm{~min}$ for PEG (20000). Samples were analysed by using standard spectrophotometry technique. Adsorbance was determined according to equation (2):

$$
q_{e}=V\left(C_{0^{-}} C_{e}\right) / m_{1}
$$

$\mathrm{C}_{\mathrm{e}}$-Equilibrium concentration of PEG in solution; $\mathrm{mg} / \mathrm{L}$

\section{Stepwise adsorption of oil}

A series simulated PEG wastewater were prepared with concentration of 50, 200, $500 \mathrm{mg} / \mathrm{L}$. Adsorption experiments for PEG were firstly carried out according to method mentioned in the adsorption of PEG. EG, saturated by different concentration of PEG solution, was filtrated with wire gauze and placed for $30.0 \mathrm{~min}$ and then it was successively used for the adsorption of oil. After equilibrium, filtration with wire gauze and placed for $30.0 \mathrm{~min}$, it was dried at $110{ }^{\circ} \mathrm{C}$ for about $7.0 \mathrm{~h}$ to insure a constant of $m_{2}$. The stepwise adsorbance of oil was calculated according to equation (1).

\section{Results and Discussion}

\section{Adsorption capacity of EG for oil}

EG was found to have much better adsorption capacity for oily materials. In the experiment, saturated adsorbance during $24.0 \mathrm{~h}$ was used to show its adsorption capacity. The value was detected as $131.3 \mathrm{~g}$ for SD300 and $127.8 \mathrm{~g}$ salad oil for every gram of EG with a expanded volume of $320 \mathrm{~mL} / \mathrm{g}$.

\section{Adsorption capacity and adsorption isotherm of EG for PEG}

Static adsorption capacities of EG for PEG (4000, 10000, 20000) were measured. Figure 1 shows a typical I type isotherm, and the equilibrium adsorbance is less than $50 \mathrm{mg} / \mathrm{g}$. The planar structure of PEG might form certain kinds of conformation on the surface of EG, which might reduce the adsorbed sites and make the further adsorption difficult. As showed in Figure 1 (b), absorbance decreases with the increase of PEG MW. Similar result was obtained as the adsorption of active carbon for $\mathrm{PEG}^{9}$. 

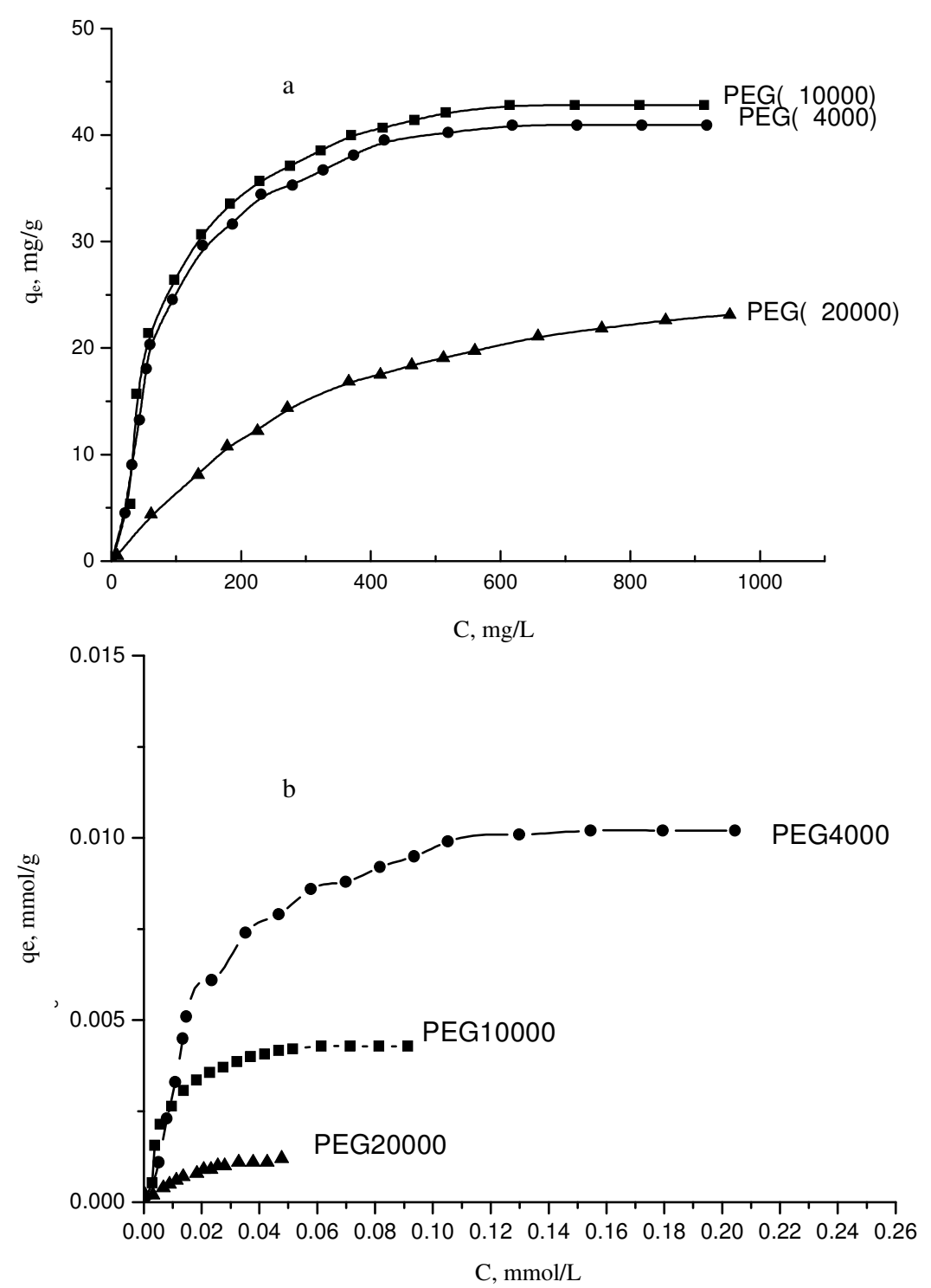

Figure 1. Adsorption isotherm of PEG (1000, 4000, 10000 and 20000) at $25{ }^{\circ} \mathrm{C}$

(a) Unit of adsorbance is defined as $\mathrm{mg} / \mathrm{g}$; (b) Unit of adsorbance is defined as $\mathrm{mmoL} / \mathrm{g}$, Langmuir equation (3) was used to treat the isotherm data. The molecule area (a) of PEG was calculated according to maximum adsorbance $\mathrm{Q}_{0}$ and total pore area as showed in Table 1.

$$
\text { Langmuir equation }^{14}: 1 / \mathrm{Q}=1 / \mathrm{Q}_{0}+\mathrm{A} /\left(\mathrm{Q}_{0} \times \mathrm{C}\right)
$$

$\mathrm{Q}_{0}$ - maximum adsorbance; mmoL/g A - The equilibrium concentration of PEG corresponding to half saturation adsorbance; $\mathrm{mg} / \mathrm{mL}$.

Results showed in Figure 2 suggest a linear relationship between MW and molecule area $a\left[(\mathrm{~nm})^{2} /\right.$ molecule of PEG]. This suggests PEG molecules lay flat on the EG surface, and it's just the same as the adsorption of active carbon for PEG. 


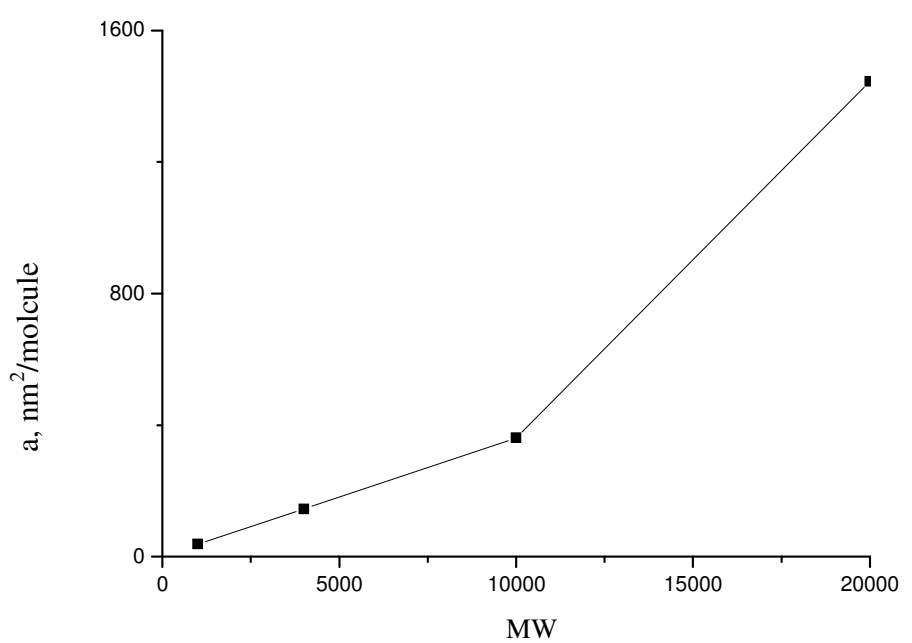

Figure 2. Relationship between PEG MW and molecule area

\section{The SEM analysis of saturated EG}

Study of static adsorption has testified EG shows higher adsorption capacity for oils (more than $100.0 \mathrm{~g} / \mathrm{g}$ ) than for PEG (less than $50 \mathrm{mg} / \mathrm{g}$ ). To further testify their different adsorption pattern, SEM analysis was carried out for EG (a), EG saturated by PEG (10000) with an equilibrium adsorbance of $42.82 \mathrm{mg} / \mathrm{g}$ (b), EG saturated by SD 300 oil (c), EG saturated by salad oil (d). Figure 3 (a) shows a special v-type structure of EG as mentioned in reference ${ }^{5}$. Compared with (a), (b) shows obvious breakage of v-type structure of EG, but pores on the surface of the worm like particles are still clear. While, (c) shows EG is filled thoroughly by SD 300 oil and (d) shows EG is filled thoroughly by salad oil. Adsorption process of oil into EG may compose of two-unit process: adsorption and filling ${ }^{7}$; "wrapping space", first-level and second-level pores of EG particles play important role in influence adsorbance. However, as proved above, the adsorption of PEG on EG belongs to monolayer adsorption, and the molecules lay flat on EG surface.

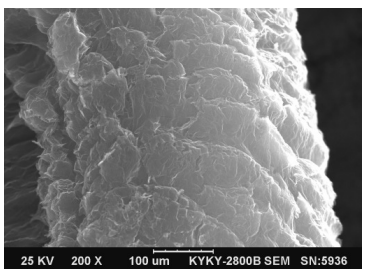

a

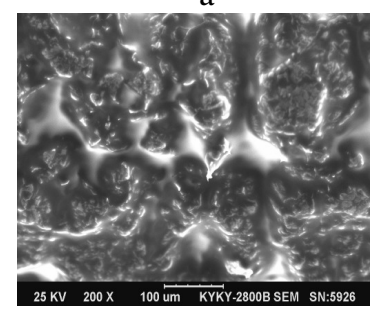

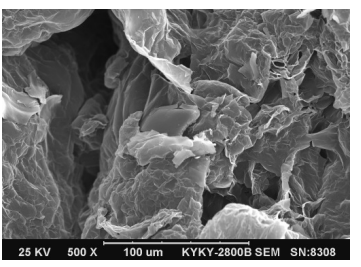

$\mathrm{b}$

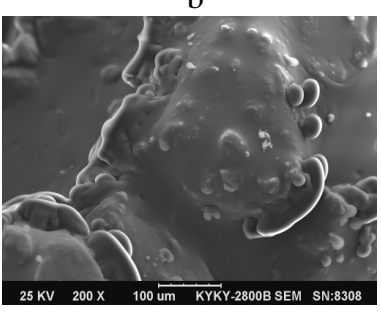

d

Figure 3. SEM micrograph of EG, (a) EG, (b) EG saturated by PEG (10000), (c) EG saturated by SD 300 oil, (d) EG saturated by salad oil 


\section{Stepwise adsorption of EG for oil-the further evidence of adsorption mechanism}

Stepwise adsorbance of oil on EG which is saturated by different concentration of PEG were detected and the results are showed in Figure $4 \& 5$ respectively. Adsorbance of oil on EG, which is saturated by de-ionized water firstly in stepwise adsorption, is regarded as blank value. No obvious difference among the adsorbance is observed.

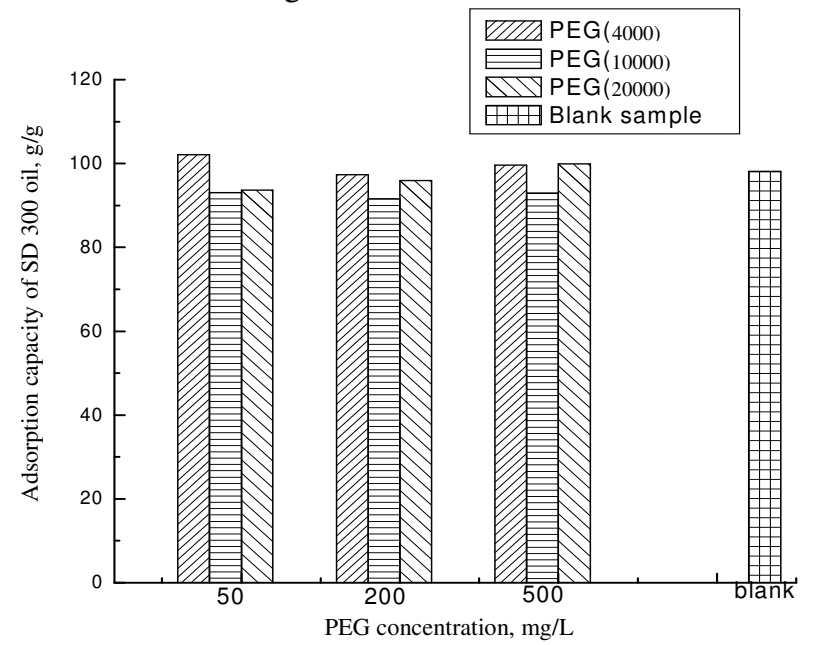

Figure 4. Stepwise adsorption capacity of SD 300 oil on EG

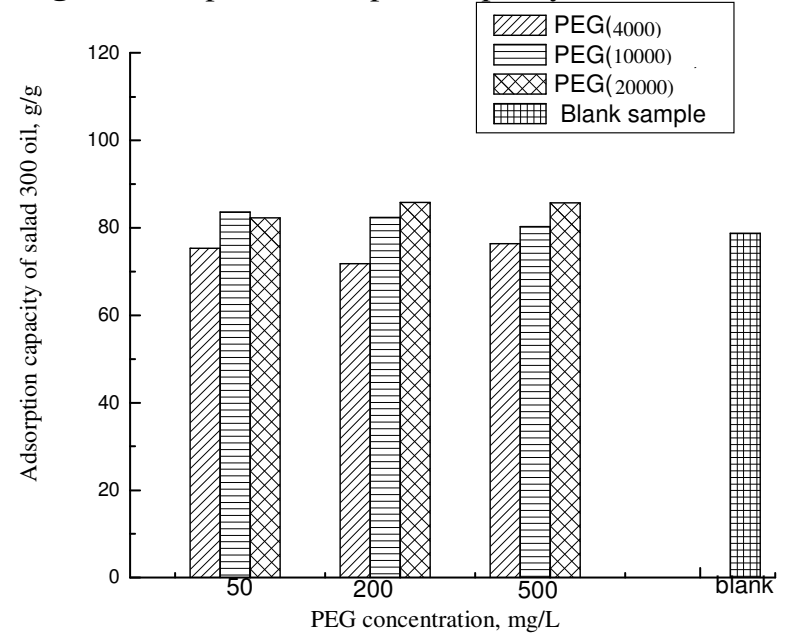

Figure 5. Stepwise adsorption capacity of salad oil on EG

To justify whether there is statistical significance or not among the adsorbance of oil in stepwise adsorption, deviation analysis has been carried out. The blank value is considered as average of deviation analysis ${ }^{9}$. Deviation both between average and every adsorbance of oil corresponding to various initial PEG concentration (in group) and deviation between average and adsorbance of oil corresponding to different kind PEG (among groups) are calculated. Results showed in Table 3 and Table 4 all give the conclusion of no statistical significance In other words, the stepwise adsorbance of oils depends neither on PEG concentration, nor on PEG molecular weight. 
Table 3. $t$-Test of stepwise adsorption adsorbance of SD 300 oil on EG

\begin{tabular}{ccc}
\hline & $t$-test in group & $t_{\text {-test among groups }}{ }^{\mathrm{b}}$ \\
\hline $\mathrm{t}_{\text {theoretical }}$ & $\mathrm{t}_{0.05,2}=4.303$ & $\mathrm{t}_{0.05,4}=2.776$ \\
$\mathrm{t}_{\text {calculated }}$ & $\mathrm{t}_{0.05,2}=0.577$ & $\mathrm{t}_{0.05,4}=0.636$ \\
\hline
\end{tabular}

${ }^{a}$ The blank adsorbance of SD 300 oil on EG is considered as an average, and deviation analysis is carried out among stepwise adsorbance of SD 300 oil corresponding to various initial concentration of PEG(10000).

b Deviation of stepwise adsorbance of SD 300 oil on EG is calculated between PEG(20000) and PEG(10000), 12 groups of data are used.

Table 4. $t$-Test of stepwise adsorption adsorbance of salad oil on EG

\begin{tabular}{ccc}
\hline & $t$-test in group & \\
& & $t$-test among groups \\
& $\mathrm{b}$ \\
\hline $\mathrm{t}_{\text {theoretical }}$ & $\mathrm{t}_{0.05,2}=4.303$ & $\mathrm{t}_{0.05,4}=2.776$ \\
$\mathrm{t}_{\text {calculated }}$ & $\mathrm{t}_{0.05,2}=3.059$ & $\mathrm{t}_{0.05,4}=2.765$ \\
\hline
\end{tabular}

a The blank adsorbance of salad oil on EG is considered as an average, and deviation analysis is carried out among stepwise adsorbance of salad oil corresponding to various initial concentration of PEG(10000).

b Deviation of stepwise adsorbance of salad oil on EG is calculated between PEG(20000) and PEG(10000), 12 groups of data are used.

Stepwise adsorbance of oil declines markedly, EG saturated firstly by PEG, still has an average adsorption capacity of $98 \mathrm{~g} / \mathrm{g}$ for SD300 oil and $85 \mathrm{~g} / \mathrm{g}$ for salad oil and it does not change with the initial PEG concentration. This diminished value should be caused by the breakage of v-type structure (as showed in Figure 3 (b)), deformation of pores and shatter of the particles under surface tension between EG and water during the adsorption of PEG. The existence of stepwise adsorbance of oil testifies a different adsorption mechanism between EG and PEG, EG and oil. Adsorption of oil on EG is mainly filling in first-level and second-level pores; once the structure is destroy, the adsorption capacity of oil would decreased markedly. Adsorption of PEG is monolayer, and they lay flat on the surface of EG. EG, which has been used for the treatment of PEG wastewater, can be used sequentially for the remove of oils contamination.

\section{Conclusion}

This study has provided an insight into adsorption capacity, adsorption mechanism of SD 300 oil, salad oil and PEG (4000, 10000 and 20000) on EG. Results can be summarized as following:

(1) EG has better adsorption capacity for oils. EG with an expanded volume of $320 \mathrm{~mL} / \mathrm{g}$ has an adsorption capacity of $131.3 \mathrm{~g} / \mathrm{g}$ for SD 300 oil and $127.8 \mathrm{~g} / \mathrm{g}$ for salad oil and the adsorption is mainly filling.

(2) Adsorption of PEG on EG is monolayer and PEG molecules lay flat on the surface of pore, which causes smaller adsorbance. EG, saturated by PEG, still holds abundant pores on the surface of the worm like particles. In the stepwise adsorption of oil on EG, which is saturated by different PEG with different concentration, there is no statistical significance among stepwise adsorbance of oil. The adsorbent could be used for the elimination of PEG and oil step by step.

\section{Acknowledgments}

This study was supported by Doctor Foundation of Hebei province Education Office (China, No.B2004402) and Doctor Foundation of Hebei University. We gratefully acknowledge their support during the study. 


\section{References}

1. Zhou W, Zhao H, Hu X F, Dong J, Shen W C and Kang F Y, Tech Water Treat., 2001, 27(6), 335.

2. Kang F Y, Zeng Y P, Zhao H, Wang H N, Wang L N, Shen W C and Inagaki M, New Carbon Mater., 2003, 18(3), 161.

3. Pang X Y, Ren H L, Gong F and You T T, J Hebei Univ (Nat Sci)., 2008, 28(5), 512.

4. $\quad$ Pang X Y, Lv P, Feng Y Q and Liu X W, Environ Sci An Indian J., 2008, 3(2), 150.

5. Zhao H, Zhou W, Cao N Z, Shen W C and Zheng Y P, Mater Sci Eng., 2002, 20(2), 153.

6. Cao N Z, Shen W C, Wen S Z, Liu Y J, Wang Z D and Inagaki M, Chinese Crabon, 1996, $2,1$.

7. Zheng Y P, Wang H N, Kang F Y, Wang L N and Inagaki M, Carbon, 2004, 42(13), 2603.

8. Inagaki M, Shibata K, Setou S, Toyoda M and Aizawa J I, Desalination, 2000, 128(3), 219-222.

9. Zhao Z G and Gu X R, Acta Phys Chim Sci, 1989, 5, 185.

10. Chang C F, Chang C Y, Tsai W T and Wu S C, J Colloid Interface Sci., 2000, 232(1), 207.

11. Chang C Y, Tsai W T, Ing C H and Chang C F, J Colloid Interface Sci., 2003, 260(2), 273.

12. Pang X Y, Dong Z Y and Li X L, Chinese Carbon, 2007, 2, 35.

13. Country Environ. Prot. Bureau, The Environmental Protection Industry Standard's Republic of China HJ/T 271-2006-Specifications for Environmental Protection Product Ultrafiltration Equipment, 2006.

14. Shao Z H, Zhou M H and Lei L C, Acta Sci Circumstantiate, 2005, 25, 655. 


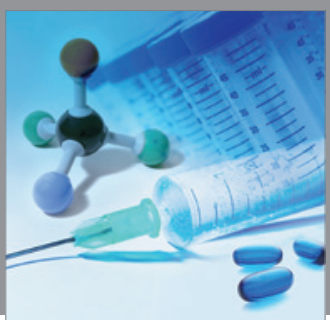

International Journal of

Medicinal Chemistry

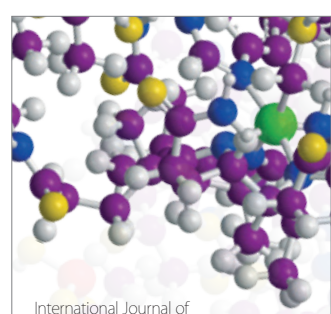

Carbohydrate Chemistry

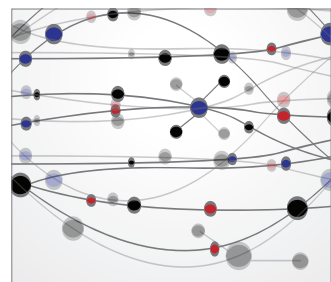

The Scientific World Journal
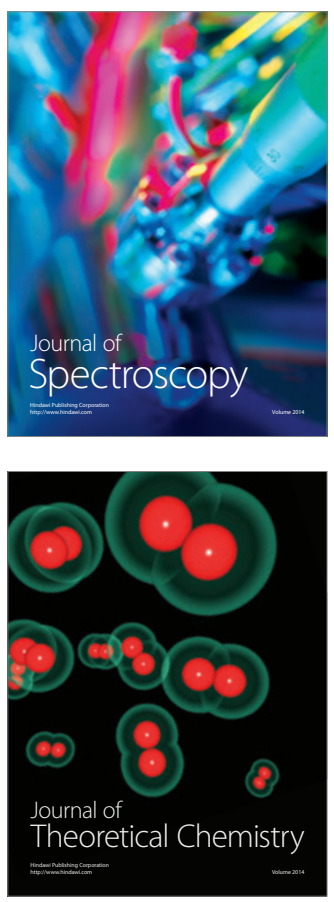
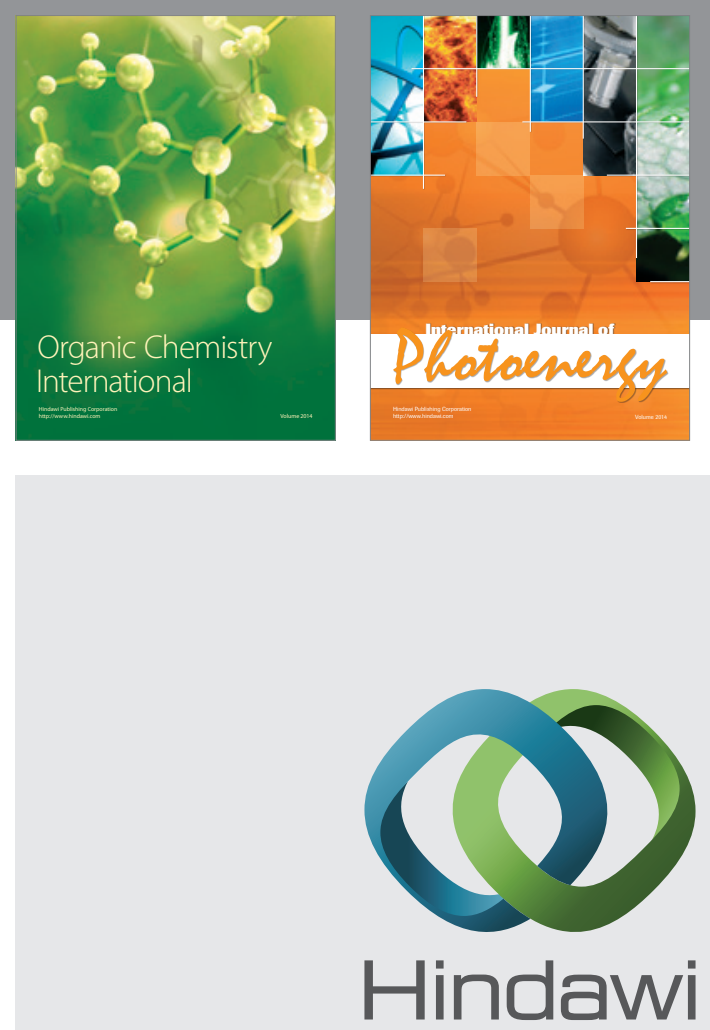

Submit your manuscripts at

http://www.hindawi.com
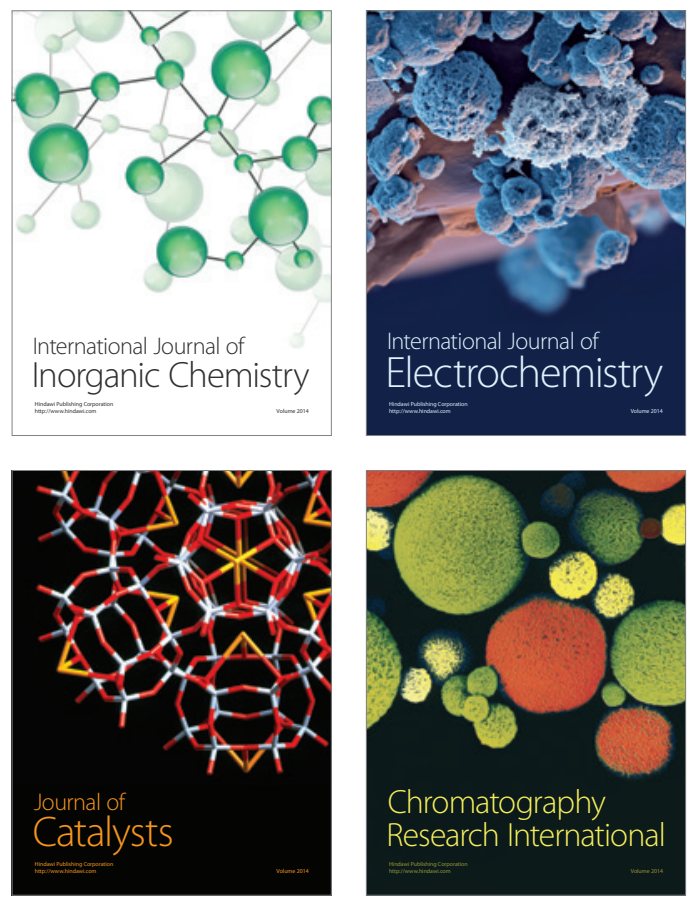
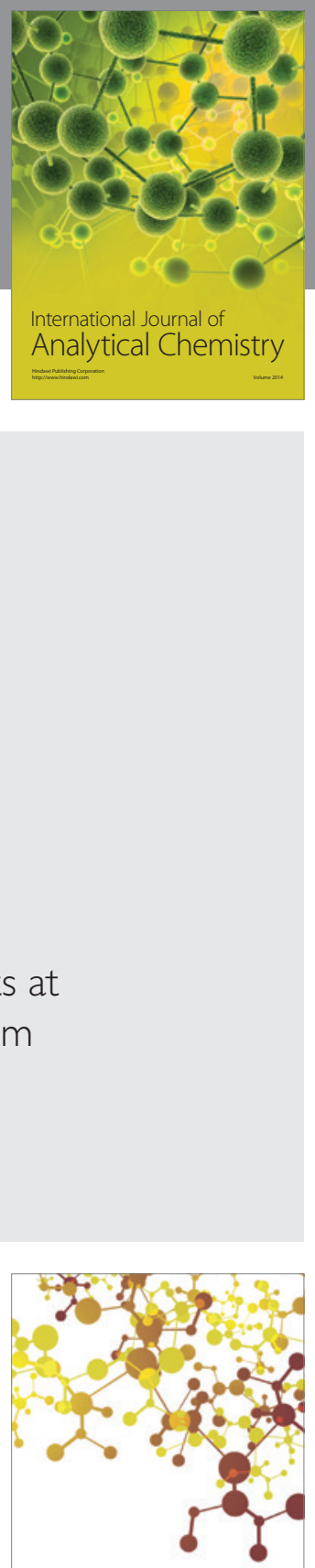

Journal of

Applied Chemistry
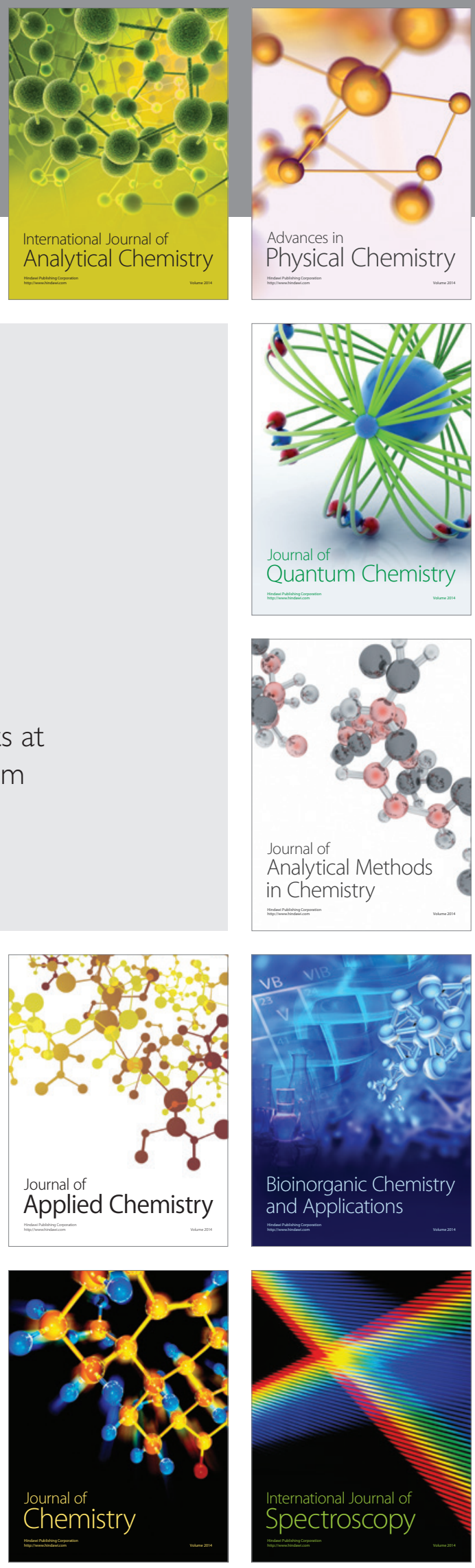